\title{
Sexual Autonomy and Self-reported Sexually Transmitted Infections Among Sub-saharan African Women in Sexual Unions
}

Collins Adu ( $\square$ collinsadu80@yahoo.com )

Kwame Nkrumah University of Science and Technology https://orcid.org/0000-0002-1300-6327

Aliu Mohammed

University of Cape Coast

Eugene Budu

University of Cape Coast

James Boadu Frimpong

University of Cape Coast

Justice Kannor Tetteh

University of Cape Coast

\section{Bright Opoku Ahinkorah}

University of Technology Sydney

Abdul-Aziz Seidu

James Cook University

\section{Research Article}

Keywords: Public health, Sexual autonomy, STIs, Sub-Saharan Africa, Women

Posted Date: June 28th, 2021

DOl: https://doi.org/10.21203/rs.3.rs-639480/v1

License: (9) This work is licensed under a Creative Commons Attribution 4.0 International License. Read Full License 


\section{Abstract}

\section{Background}

Sexually transmitted infections (STIs) remain a major public health challenge worldwide. Despite the importance of sexual autonomy in the prevention and control of sexual and reproductive health disorders such as STIs, there are limited studies on the possible relationship between women's sexual autonomy and self-reported STIs, especially in sub-Saharan Africa (SSA). This study, therefore, examined the association between sexual autonomy and self-reported STIs among women in sexual unions in SSA.

\section{Methods}

Data from the Demographic and Health Survey (DHS) of 31 countries in SSA conducted between 2010 and 2019 were analysed. A total of 234,310 women in sexual unions were included in the study. Data were analysed using binary logistic regression models and the results were presented as crude odds ratios (cORs) and adjusted odds ratios (aORs) at 95\% confidence interval (Cl).

\section{Results}

The prevalence of self-reported STIs among women in sexual unions in SSA was $5.8 \%$. Approximately $83.0 \%$ of the women surveyed had sexual autonomy. Women who had no sexual autonomy were less likely to have self-reported STIs ( $\mathrm{COR}=0.52$, Cl: 0.46-0.54), compared to those who had sexual autonomy. Additionally, higher odds of self-reported STIs were found among women aged 25-29, compared to those aged 15-19 (aOR=1.21, $\mathrm{Cl}: 1.09-1.35)$; those who reside in urban areas, compared to those who reside in rural areas ( $\mathrm{aOR}=1.51, \mathrm{Cl}: 1.37-1.66)$ and those who were cohabiting, compared to those who were married ( $\mathrm{aOR}=1.65, \mathrm{Cl}: 1.52-1.79)$. On the other hand, lower odds of self-reported STIs were found among women who were exposed to newspapers $(\mathrm{aOR}=0.89, \mathrm{Cl}: 0.82-0.95)$, those whose partners had primary education ( $\mathrm{aOR}=0.84, \mathrm{Cl}: 0.78-0.91)$, those who were not exposed to radio ( $\mathrm{aOR}=0.84, \mathrm{Cl}: 0.79-0.89$ ), and working women $(\mathrm{aOR}=0.86, \mathrm{Cl}: 0.80-0.93)$.

\section{Conclusion}

Findings from this study suggest that sexual autonomy is a significant predictor of self-reported STIs among women in sexual unions in SSA. Thus, instituting policies and programs that empower women and improve their levels of sexual autonomy may result in increased self-reporting of symptoms associated with STIs which subsequently help in minimising STI-related complications. Also, policies aimed at enhancing women's sexual autonomy may reduce the burden of STIs in SSA, especially among women in sexual unions.

\section{Background}

Sexually transmitted infections (STIs) remain a major public health challenge affecting many individuals across the globe ${ }^{1,2}$. Chlamydia, syphilis, trichomoniasis, human papilloma virus (HPV), and gonorrhea are 
among the common STIs that confront individuals worldwide ${ }^{3,4}$. Even though most STIs are curable, their detrimental and rippling effects on the health and wellbeing of individuals and their families are enormous $^{5}$. Evidence shows that STIs may result in adverse conditions such as infertility, ectopic pregnancy, pelvic inflammatory disease, and loss of eye sight as well as increasing risk of contracting HIV $^{1,6,7,8,9}$.

Contemporarily, the methods of prevention and treatment of STIs have seen more scientific and technological advancements, making them cheaper and more effective ${ }^{5}$. Nonetheless, STI prevalence continues to rise. For example, the World Health Organization (WHO) reported that new cases of STIs in 2012 stood at nearly 367 million worldwide ${ }^{10}$. The infections were pervasive in sub-Saharan Africa (SSA), Latin America and Asia, with SSA alone contributing to approximately 93 million cases of STIs every year $^{3}$. This prompts urgent need for in-depth focus on this public health issue in the sub-region. One possible way of providing apt prevention and control interventions for people who have contracted STIs is by self-reporting incidence of STIs at the health facility for subsequent treatment ${ }^{11,12,13}$. Hence, studies that focus on self-reported STIS (SR-STIS) are valuable for formulating and strengthening public health policies and interventions.

Evidence from scientific investigations show that sexual autonomy contributes significantly to the odds of contracting STIs ${ }^{14,15}$. Women's sexual autonomy is a woman's ability to make informed decisions about her own sexual health such as abstaining from sexual intercourse, using condom and contraception or opting for abortion services ${ }^{16,17}$. Women's sexual autonomy is also closely linked to empowerment which is regarded as an essential measure of a society's level of development ${ }^{18,19,20}$. Essentially, women who are sexually autonomous are to some extent shielded from unwanted pregnancies and they often have lower odds of contracting STIs compared to women who are not sexually autonomous ${ }^{15,20}$. However, in the case of self-reported STIs, women with sexual autonomy often have higher levels of awareness regarding their sexual and reproductive health ${ }^{6,21}$ which often leads to increased likelihood of detecting and reporting symptoms of STIs compared to those without sexual autonomy ${ }^{13}$.

Despite the health benefits of women's sexual autonomy and its possible association with self-reported STIs, little research has been done on this phenomenon in SSA. Meanwhile, the few studies conducted only focused on self-reported STIs among men in $\mathrm{SSA}^{22}$, men who have sex with men (MSM) and the aged $^{23,24}$. Therefore, this study sought to examine the prevalence of sexual autonomy and self-reported STIs and the relationship between these variables among women in sexual unions in SSA. Findings of the study could help direct policies and interventions aimed at reducing the prevalence of STIs by improving sexual autonomy among women in sexual unions in SSA.

\section{Methods}

\section{Data source}


The study used data from 31 sub-Saharan African countries' Demographic and Health Survey (DHS). Specifically, we used data from the women recode (IR) files. The DHS is a nationally representative survey that is conducted in over 85 low-and middle-income countries globally. It focuses on essential maternal and child health markers such as breastfeeding, fertility, family planning, infant and child mortality, immunization, maternal and child health and nutrition ${ }^{25}$. The survey employs a two-stage stratified sampling technique, which makes the data nationally representative. The study by Aliaga and Ruilin 26 provides details of the sampling process. A total of 234,310 respondents who had complete information on all the variables of interest were included in our study. We relied on the Strengthening the Reporting of Observational Studies in Epidemiology (STROBE) statement in writing the manuscript ${ }^{27}$. The dataset is freely available for download at: https://dhsprogram.com/data/available-datasets.cfm.

\section{Variables studied}

Dependent variable: Self-reported Sexually Transmitted Infections was the dependent variable in this study. It was derived by asking if a woman had a sexually transmitted infection (STI) in the last 12 months. This was confirmed by responding "yes" to having any of the ensuing conditions: an STI, having abnormal genital discharge, experiencing a genital ulcer or sore, or having an STI symptom ${ }^{36}$. This has been adopted in several previous studies as a measure of self-reported STIs $28,29,30,31$.

Explanatory variables: The main explanatory variable was sexual autonomy. This variable was a composite variable derived from "respondent can refuse sex," "respondent can ask partner to use condom," and "wife is justified in asking the husband to use condom." The response categories of these variables were: "Yes" and "No". The 'Yes' responses were coded ' 1 ' and the 'No' responses were coded ' 0 '. An index was created with all the "Yes" and "No" answers with scores stretching from 0 to 3 . The Score 0 and 1 was labelled as "No" and 2 to 3 was labelled as "Yes". A dummy variable was created with '0' score being females who did not have sexual autonomy and ' 1 ' if females who had sexual autonomy ${ }^{21}$. Other explanatory variables included in the study were age (15-19, 20-24, 25-29, 30-34, 35-39, 40-44, 4549), educational level (No education, Primary, Secondary, Higher) place of residence (Urban, Rural), wealth quintile (Poorest, Poorer, Middle, Richer, Richer), marital status (Married, Cohabiting), partners' educational level (No education, Primary, Secondary, Higher), multiple sexual partner (No, Yes), exposure to newspaper (No, Yes), radio (No, Yes), and television (No, Yes), and occupation (Not working, Working). These variables were determined a priori.

\section{Data analyses}

Data was analysed with Stata version 16.0. The analysis was done in three steps. The first step was a graphical representation of the prevalence of sexual autonomy (Fig. 1) and the self-reported STIs (Fig. 2) in SSA. The second step was a bivariate analysis that showed the proportion of self-reported STI across the explanatory variables with their $p$-values which were derived from a chi-square (Table 1). Variables that showed statistical significance from the Table 1 were moved to the third step of the analysis. In the 
third step of the analysis two hierarchical logistic regression models were built. Model I looked at a bivariate analysis between the explanatory variables and self-reported STIs. Model II controlled for the effect of all the covariates and country in a multivariable logistic regression. All frequency distributions were weighted while the survey command (svy) in Stata was used to adjust for the complex sampling structure of the data in the regression analyses. 
Table 1

Description of study sample

\begin{tabular}{|llll|}
\hline Country & Year of survey & Weighted N & Weighted \% \\
\hline Angola & & 6255 & 2.7 \\
\hline Burkina Faso & 2010 & 12993 & 5.5 \\
\hline Benin & $2018-19$ & 10130 & 4.3 \\
\hline Burundi & $2016-17$ & 9493 & 4.0 \\
\hline Congo DR & $2013-14$ & 10327 & 4.4 \\
\hline Congo & $2011-12$ & 5689 & 2.4 \\
\hline Cote D'Ivorie & $2011-12$ & 5296 & 2.3 \\
\hline Cameroon & 2018 & 7435 & 3.2 \\
\hline Ethiopia & 2016 & 8834 & 3.8 \\
\hline Gabon & 2012 & 3785 & 1.6 \\
\hline Ghana & 2014 & 4946 & 2.1 \\
\hline Gambia & 2013 & 6112 & 2.6 \\
\hline Guinea & 2018 & 5829 & 2.5 \\
\hline Kenya & 2014 & 8086 & 3.4 \\
\hline Comoros & 2012 & 2377 & 1.0 \\
\hline Liberia & 2013 & 5050 & 2.2 \\
\hline Lesotho & 2014 & 1687 & 0.7 \\
\hline Mali & 2018 & 7555 & 3.2 \\
\hline Malawi & $2015-16$ & 15501 & 6.6 \\
\hline Nigeria & 2018 & 20060 & 8.6 \\
\hline Niger & 2012 & 7947 & 3.4 \\
\hline Namibia & 2013 & 2771 & 1.2 \\
\hline Rwanda & $2014-15$ & 6755 & 2.9 \\
\hline Sierra Leone & 2019 & 8821 & 3.8 \\
\hline Senegal & $2010-11$ & 8473 & 3.6 \\
\hline Chad & $2014-15$ & 10137 & 4.3 \\
\hline Togo & 5545 & 2.4 \\
\hline
\end{tabular}




\begin{tabular}{|llll|}
\hline Country & Year of survey & Weighted N & Weighted \% \\
\hline Uganda & 2016 & 10494 & 4.5 \\
\hline South Africa & 2016 & 2828 & 1.2 \\
\hline Zambia & 2015 & 7233 & 3.1 \\
\hline Zimbabwe & & 5866 & 2.5 \\
\hline Total & & 234310 & 100 \\
\hline
\end{tabular}

\section{Results}

\section{Prevalence of self-reported STIs and sexual autonomy among women in sexual union in SSA}

Figure 1 presents results on the prevalence of self-reported STIs among women in sexual union in subSaharan African countries. On average, the prevalence of self-reported STIs was $5.8 \%$. Women in Liberia had the highest prevalence (30.9\%) while those from Ethiopia had the lowest $(0.3 \%)$. In terms of the proportion of women who had sexual autonomy, prevalence of $83.1 \%$ was recorded in all the countries considered in this study. Women in Rwanda had the highest prevalence (99.5\%) while those from Chad had the lowest (16.5\%) (Fig. 2).

\section{Distribution of background Characteristics and Self-reported STls}

We found a significant association between sexual autonomy and self-reported STIs among women in sexual union in SSA. Specifically, self-reported STIs was higher among women who had sexual autonomy (6.2\%), compared to those who had no sexual autonomy (3.4\%). There were significant variations in selfreported STIs across the socio-demographic characteristics of the women (marital status, multiple sexual partners, wealth quintile, exposure to radio, exposure to television, partner's educational level, and place of residence) (Table 2). 
Table 2

background Characteristics and Self-reported STIs

\begin{tabular}{|c|c|c|c|c|}
\hline Variables & Weighted N & Weighted \% & Self-reported STI & p-value \\
\hline Sexual autonomy & & & & $<0.0001$ \\
\hline No & 39782 & 17.0 & 3.4 & \\
\hline Yes & 194528 & 83.0 & 6.2 & \\
\hline Age & & & & $<0.0001$ \\
\hline $15-19$ & 14507 & 6.2 & 4.8 & \\
\hline $20-24$ & 39793 & 17.0 & 6.0 & \\
\hline $25-29$ & 50961 & 21.7 & 6.4 & \\
\hline $30-34$ & 44453 & 19.0 & 6.2 & \\
\hline $35-39$ & 37588 & 16.0 & 5.9 & \\
\hline $40-44$ & 26383 & 11.3 & 4.8 & \\
\hline $45-49$ & 20624 & 8.8 & 4.4 & \\
\hline Marital status & & & & $<0.0001$ \\
\hline Married & 190503 & 81.3 & 5.0 & \\
\hline Cohabiting & 43807 & 18.7 & 8.9 & \\
\hline Occupation & & & & $<0.0001$ \\
\hline Working & 63177 & 27.0 & 5.0 & \\
\hline Not working & 171133 & 73.0 & 6.1 & \\
\hline Multiple sexual partners & & & & 0.0631 \\
\hline No & 224844 & 96.0 & 5.7 & \\
\hline Yes & 9466 & 4.0 & 6.9 & \\
\hline Wealth quintile & & & & $<0.0001$ \\
\hline Poorest & 44255 & 18.9 & 4.8 & \\
\hline Poorer & 47087 & 20.1 & 5.2 & \\
\hline Middle & 46876 & 20.0 & 5.7 & \\
\hline Richer & 47933 & 20.5 & 6.4 & \\
\hline
\end{tabular}




\begin{tabular}{|c|c|c|c|c|}
\hline Variables & Weighted N & Weighted \% & Self-reported STI & p-value \\
\hline Richest & 48158 & 20.5 & 6.6 & \\
\hline Exposure to newspaper & & & & 0.0001 \\
\hline No & 196418 & 83.8 & 5.6 & \\
\hline Yes & 37892 & 16.2 & 6.8 & \\
\hline Exposure to radio & & & & $<0.0001$ \\
\hline No & 96508 & 41.2 & 5.0 & \\
\hline Yes & 137802 & 58.8 & 6.3 & \\
\hline Exposure to television & & & & $<0.0001$ \\
\hline No & 140484 & 60.0 & 5.2 & \\
\hline Yes & 96826 & 40.0 & 6.6 & \\
\hline Partner's educational level & & & & $<0.0001$ \\
\hline No education & 81548 & 34.8 & 4.7 & \\
\hline Primary & 61457 & 26.2 & 5.2 & \\
\hline Secondary & 71144 & 30.4 & 7.2 & \\
\hline Higher & 20160 & 8.6 & 6.8 & \\
\hline Place of residence & & & & $<0.0001$ \\
\hline Urban & 81726 & 34.9 & 7.5 & \\
\hline Rural & 152584 & 65.1 & 4.9 & \\
\hline${ }^{*} p<0.05,{ }^{* \star} p<0.01,{ }^{\star \star \star} p<0$. & & & & \\
\hline
\end{tabular}

Binary logistic regression analysis on the sexual autonomy and self-reported STIs among women in sexual union in SSA

Table 3 shows results on the association between sexual autonomy and self-reported STIs among women in sub-Saharan Africa. We found that compared to women who had sexual autonomy, those who had no sexual autonomy were less likely to have self-reported STIs (COR $=0.52, \mathrm{Cl}: 0.46-0.54$ ) and this persisted after controlling for important covariates $(\mathrm{aOR}=0.57, \mathrm{Cl}$ : $0.52-0.64)$. In terms of the countryspecific results, women who had sexual autonomy were less likely to have self-reported STIs in Lesotho $(\mathrm{aOR}=0.02, \mathrm{Cl}: 0.01-0.16)$, Chad $(\mathrm{aOR}=0.05, \mathrm{Cl}: 0.02-0.10)$, Benin ( $\mathrm{aOR}=0.15, \mathrm{Cl}: 0.11-0.19)$, Uganda $(\mathrm{aOR}=0.42, \mathrm{Cl}: 0.24-0.72)$, Burkina Faso ( $\mathrm{aOR}=0.51, \mathrm{Cl}: 0.32-0.79)$, Guinea (aOR=0.67, Cl: 0.55-0.81), and Nigeria (aOR = 0.75, Cl: 0.62-0.91) (see Model II of Table 4). 
Table 3

Sexual autonomy and self-reported STIS among women in SSA

\section{Country}

Sexual autonomy

No

Yes

Age

$15-19$

$20-24$

$25-29$

$30-34$

$35-39$

$40-44$

$45-49$

\section{Marital status}

Married

Cohabiting

Occupation

Working

Not working

\section{Wealth quintile}

Poorest

$0.73^{\star \star \star}(0.66-0.80)$
Reference (1.0)

Reference (1.0)

$1.24^{\star \star \star}(1.011-1.38)$

$1.30^{\star \star \star}(1.17-1.45)$

$1.26^{\star \star \star}(1.13-1.40)$

$1.20^{\star \star}(1.08-1.34)$

$0.96(0.81-1.08)$

$0.88^{\star}(0.77-1.00)$

Reference (1.0)

$1.81^{\star \star \star}(1.66-1.97)$

$0.84^{\star \star \star}(0.78-0.91)$

Reference (1.0)
Poorer

Middle

Richer $0.77^{\star \star \star}(0.70-0.85)$

$0.86^{\star \star \star}(0.78-0.94)$

$0.96(0.88-1.05)$
Model II $0.57^{\star \star \star}(0.52-0.64)$

Reference (1.0)
Reference (1.0)

$1.15^{*}(1.03-1.29)$

$1.21^{\star \star \star}(1.09-1.35)$

$1.19^{\star \star}(1.07-1.32)$

$1.14^{\star}(1.02-1.28)$

$0.92(0.82-1.04)$

$0.87^{\star}(0.76-0.99)$
Reference (1.0)

$1.65^{\star \star \star}(1.52-1.79)$ $0.86^{\star \star \star}(0.80-0.93)$

Reference (1.0)

Exponentiated coefficients; $95 \%$ confidence intervals in brackets; AOR adjusted Odds Ratios;COR: Crude Odds Ratios; $\mathrm{Cl}$ Confidence Interval

${ }^{*} p<0.05,{ }^{* *} p<0.01,{ }^{* \star *} p<0.001$ 


\begin{tabular}{|c|c|c|}
\hline Country & Model I & Model II \\
\hline Richest & Reference (1.0) & Reference (1.0) \\
\hline \multicolumn{3}{|l|}{ Exposure to newspaper } \\
\hline No & Reference (1.0) & Reference (1.0) \\
\hline Yes & $1.18^{\star \star \star}(1.09-1.27)$ & $0.89^{\star \star \star}(0.82-0.95)$ \\
\hline \multicolumn{3}{|l|}{ Exposure to radio } \\
\hline No & $0.74^{\star \star \star}(0.70-0.79)$ & $0.84^{\star \star \star}(0.79-0.89)$ \\
\hline Yes & Reference (1.0) & Reference (1.0) \\
\hline \multicolumn{3}{|l|}{ Exposure to television } \\
\hline No & Reference (1.0) & Reference (1.0) \\
\hline Yes & $1.34^{\star \star \star}(0.26-1.43)$ & $1.02(0.94-1.10)$ \\
\hline \multicolumn{3}{|l|}{ Partner's educational level } \\
\hline No education & Reference (1.0) & Reference (1.0) \\
\hline Primary & $1.02(0.94-1.10)$ & $0.84^{\star \star \star}(0.78-0.91)$ \\
\hline Secondary & $1.44^{\star \star \star}(1.32-1.56)$ & $1.05(0.87-1.11)$ \\
\hline Higher & $1.37^{\star \star \star}(1.23-1.52)$ & $0.99(0.87-1.11)$ \\
\hline \multicolumn{3}{|l|}{ Place of residence } \\
\hline Urban & $1.60^{\star \star \star}(1.48-1.74)$ & $1.51^{\star \star \star}(1.37-1.66)$ \\
\hline Rural & Reference (1.0) & Reference (1.0) \\
\hline \multicolumn{3}{|c|}{$\begin{array}{l}\text { Exponentiated coefficients; } 95 \% \text { confidence intervals in brackets; AOR adjusted Odds Ratios;COR: } \\
\text { Crude Odds Ratios; Cl Confidence Interval }\end{array}$} \\
\hline${ }^{*} p<0.05,{ }^{* *} p<0.01,{ }^{* * *} p<0.001$ & & \\
\hline
\end{tabular}


Table 4

Sexual autonomy and self-reported STIs in respective countries in SSA

\begin{tabular}{|c|c|c|}
\hline Country & Model I & Model II \\
\hline Angola & $0.47^{\star \star \star}(0.35-0.62)$ & $0.77(0.57-1.04)$ \\
\hline Burkina Faso & $0.42^{\star \star \star}(0.27-0.66)$ & $0.51^{\star \star}(0.32-0.79)$ \\
\hline Benin & $0.15^{\star \star \star}(0.12-0.20)$ & $0.15^{\star \star \star}(0.11-0.19)$ \\
\hline Burundi & $0.88(0.58-1.32)$ & $1.01(0.67-1.52)$ \\
\hline Congo DR & $0.84(0.69-1.01)$ & $1.00(0.82-1.21)$ \\
\hline Congo & $1.17(0.77-1.77)$ & $1.34(0.87-2.06)$ \\
\hline Cote D'Ivorie & $0.87(0.65-1.17)$ & $0.98(0.72-1.33)$ \\
\hline Cameroon & $0.45^{\star \star \star}(0.29-0.70)$ & $0.60^{\star \star}(0.38-0.94)$ \\
\hline Ethiopia & $0.66(0.34-1.27)$ & $0.80(0.40-1.61)$ \\
\hline Gabon & $1.28(0.64-2.57)$ & $1.50(0.73-3.05)$ \\
\hline Ghana & $1.26(0.73-2.15)$ & $1.31(0.76-2.28)$ \\
\hline Gambia & $0.74(0.41-1.31)$ & $0.83(0.46-1.01)$ \\
\hline Guinea & $0.63^{\star \star \star}(0.52-0.75)$ & $0.67^{\star \star \star}(0.55-0.81)$ \\
\hline Kenya & $0.36^{\star \star}(0.16-0.80)$ & $0.39^{*}(0.17-0.92)$ \\
\hline Comoros & $1.48(0.70-3.16)$ & $1.37(0.62-3.03)$ \\
\hline Liberia & $0.99(0.80-1.21)$ & $1.13(0.91-1.40)$ \\
\hline Lesotho & $0.05^{\star \star \star}(0.03-0.06)$ & $0.02^{\star \star \star}(0.01-0.16)$ \\
\hline Mali & $0.97(0.84-1.11)$ & $1.16^{\star}(1.00-1.34)$ \\
\hline Malawi & $0.67(0.43-1.04)$ & $0.65^{\star}(0.42-1.02)$ \\
\hline Nigeria & $0.75^{\star \star}(0.63-0.91)$ & $0.75^{\star \star \star}(0.62-0.91)$ \\
\hline Niger & $0.78(0.47-1.31)$ & $0.93(0.55-1.57)$ \\
\hline Namibia & $1.29(0.40-4.18)$ & $1.56(0.47-5.19)$ \\
\hline
\end{tabular}

Exponentiated coefficients; 95\% confidence intervals in brackets; AOR adjusted Odds Ratios;COR: Crude Odds Ratios; $\mathrm{Cl}$ Confidence Interval

${ }^{*} p<0.05,{ }^{* *} p<0.01,{ }^{* * *} p<0.001$ 


\begin{tabular}{|c|c|c|}
\hline Country & Model I & Model II \\
\hline Rwanda & $1.47(0.35-6.11)$ & $1.74(0.41-7.35)$ \\
\hline Sierra Leone & $0.38^{\star \star \star}(0.30-0.50)$ & $0.45^{\star \star \star}(0.35-0.59)$ \\
\hline Senegal & $0.54^{*}(0.30-0.95)$ & $0.66(0.37-1.18)$ \\
\hline Chad & $0.04^{\star \star \star}(0.02-0.89)$ & $0.05^{\star \star \star}(0.02-0.10)$ \\
\hline Togo & $0.52(0.26-1.02)$ & $0.65(0.32-1.30)$ \\
\hline Uganda & $0.37^{\star \star \star}(0.22-0.64)$ & $0.42^{\star \star \star}(0.24-0.72)$ \\
\hline South Africa & $0.58^{\star}(0.31-1.02)$ & $0.54^{*}(0.29-0.99)$ \\
\hline Zambia & $0.67(0.39-1.15)$ & $0.67(0.39-1.15)$ \\
\hline Zimbabwe & $0.33(0.08-1.35)$ & $0.33(0.08-1.34)$ \\
\hline \multicolumn{3}{|c|}{$\begin{array}{l}\text { Exponentiated coefficients; } 95 \% \text { confidence intervals in brackets; AOR adjusted Odds Ratios;COR: } \\
\text { Crude Odds Ratios; Cl Confidence Interval }\end{array}$} \\
\hline \multicolumn{3}{|c|}{${ }^{*} p<0.05,{ }^{* *} p<0.01,{ }^{* \star *} p<0.001$} \\
\hline
\end{tabular}

Higher odds of self-reported STIs were found among women aged 25-29 (aOR=1.21, Cl: 1.09-1.35), compared to those aged 15-19; those who reside in urban areas (aOR $=1.51, \mathrm{Cl}: 1.37-1.66)$ compared to those who reside in rural areas and those who were cohabiting ( $\mathrm{aOR}=1.65, \mathrm{Cl}: 1.52-1.79)$ compared to those who were married (see Model II of Table 3). Lower odds of self-reported STIs were found among women who were exposed to newspapers $(\mathrm{aOR}=0.89, \mathrm{Cl}: 0.82-0.95)$, those whose partners had primary education $(\mathrm{aOR}=0.84, \mathrm{Cl}: 0.78-0.91)$, those who were not exposed to radio $(\mathrm{aOR}=0.84, \mathrm{Cl}: 0.79-0.89)$, and working women $(\mathrm{aOR}=0.86, \mathrm{Cl}$ : $0.80-0.93)$ (see Model II of Table 3 ).

\section{Discussion}

This study examined the association between sexual autonomy and self-reported STIs among women in sexual unions using data from DHS of 31 countries in SSA. The findings revealed that the prevalence of self-reported STIs among the women was $5.8 \%$, and $83.1 \%$ of the women surveyed had sexual autonomy. Also, the study showed that there was significant association between sexual autonomy and self-reported STIs among women in sexual unions in SSA. Specifically, women who had sexual autonomy were more likely to have self-reported STIs compared to those who had no sexual autonomy. This finding persisted even after controlling for marital status, multiple sexual partners, wealth quintile, exposure to radio, exposure to television, partner's educational level and place of residence. 
In this study, the overall prevalence of self-reported STIs among women in sexual unions in SSA was $5.8 \%$, and it ranged from $0.3 \%$ in Ethiopia to $30.9 \%$ in Liberia. Similar findings were reported in previous studies in SSA albeit at the individual country level ${ }^{32,33}$. A recent multi-country study by Seidu et al. ${ }^{22}$ reported similar but slightly lower prevalence of self-reported STIs (3.8\%) among sexually active men in SSA. Perhaps, the higher prevalence figure recorded in the present study (5.8\%) vis-à-vis the study by Seidu et al. ${ }^{22}$ underscores the vulnerability of women to STIs relative to men ${ }^{34}$. This calls for increased attention and interventions towards addressing the issue of STIs among women in sexual unions in SSA. Meanwhile, the overall prevalence of STIs reported in the present study (5.8\%) is lower than the $19.4 \%$ reported by $\mathrm{WHO}^{35}$. The variations in prevalence could be attributed to the differences in time frames for the studies and methods used in data collection. Whereas the WHO's study relied on clinically confirmed incidence data on four curable STIs (Chlamydia, syphilis, trichomonas and gonorrhea) to determine prevalence, the present study used self-reported data on symptoms of STIs which include having abnormal genital discharge, experiencing a genital ulcer, or having an STI symptom ${ }^{36}$. Meanwhile, many STIs among women are asymptomatic ${ }^{6}$ which might have accounted for the low prevalence rate in this study. This calls for increased use of laboratory based or diagnostic studies in determining the prevalence of STIs.

Also, the study showed that women who had sexual autonomy were more likely to have self-reported STIs compared to those who had no sexual autonomy. Similar associations between sexual autonomy and self-reported STI was found by Nankinga et al. ${ }^{33}$. Available evidence suggests that women with sexual autonomy have higher levels of awareness and decision-making capacity regarding their sexual and reproductive health ${ }^{6,21}$. This may increase their likelihood to detect and report symptoms of STIs compared to those without sexual autonomy ${ }^{13}$. Thus, we speculate that the high prevalence of selfreported STIs among women with sexual autonomy is perhaps a function of their assertiveness and willingness to talk about their sexual health which include reporting STIs. Therefore, contrary to the claims by Nankinga et al. ${ }^{33}$, we argue that the high prevalence of self-reported STIs among women with sexual autonomy may not necessarily be indicative of higher incidence of STIs relative to those without sexual autonomy. As suggested by Chesson et al. ${ }^{6}$ low levels of sexual health awareness as well as stigma associated with reporting of genital symptoms often curtail reporting or delay healthcare seeking for STIs among women. Thus, increasing women's level of sexual autonomy even if not protective against STIs, may increase the odds of early detection and reporting of STI-related symptoms, thereby minimizing complications associated with STIs among women. However, further laboratory-based studies are needed to ascertain whether women with sexual autonomy have higher incidence of STIS relative to those without sexual autonomy.

\section{Practical implications}

In line with WHO's Global Health Sector Strategy on STIs 2016-2021 ${ }^{34}$, this study provides important data on STI burden in SSA, especially among women in sexual unions ${ }^{34}$. The multi-country nature of the prevalence estimates improves our understanding of the burden of self-reported STIs in SSA. Additionally, 
our findings on the association between sexual autonomy and self-reported STIs is important in designing and implementing strategies aimed at reducing burden of STIs in SSA. For instance, increasing the levels of sexual autonomy among women could result in increased self-reporting and early initiation

of treatment ${ }^{11,12}$. This could minimise STI-related complications such as ectopic pregnancy, infertility, pelvic inflammatory disease and chronic abdominal pain among the women ${ }^{6}$. Even though we speculate that high prevalence of self-reported STIs among sexually autonomous women is probably due to their increased willingness to report and seek treatment compared to women without sexual autonomy, further studies are needed to ascertain this assertion.

\section{Strengths and Limitations}

The major strength of this study is the use of the most recent nationally representative cross-sectional datasets of 31 countries in SSA to examine the association between sexual autonomy and self-reported STIs among women in sexual unions. Additionally, the rigorous data collection approach and analysis technique used in the present study enhances the generalisability of our findings to other women in sexual unions in SSA. Despite these strengths, the study has some limitations which need to be acknowledged. First of all, due to the use of cross-sectional study design, only associations between sexual autonomy and self-reported STIs were adduced but not causality. Also, the DHS data does not indicate the exact type of STI among respondents which limit the interpretation of our findings.

Furthermore, the prevalence of STIs was limited to self-report and not medically diagnosed or laboratory confirmed which could limit the interpretation of the prevalence of STI among the women. Finally, there is a possibility of underreporting of STIs since some of the women might give socially desirable answers which could create biases in the study findings.

\section{Conclusion}

Findings from this study suggest that sexual autonomy is a significant predictor of self-reported STIs among women in sexual unions in SSA. Thus, instituting policies and programs that empower women and improve their levels of sexual autonomy may result in increased self-reporting of symptoms associated with STIs which subsequently help in minimising STI-related complications. Also, policies aimed at enhancing women's sexual autonomy may reduce the burden of STIs in SSA, especially among women in sexual unions.

\section{Abbreviations}

SSA: sub-Saharan Africa

STIs: sexually transmitted infections

DHS: demographic and health survey

aOR: adjusted odds ratio 
cOR: crude odds ratio

Cl: confidence interval

SR-STIs: self-reported sexually transmitted infections

WHO: World Health Organization

\section{Declarations}

\section{Acknowledgement}

Not applicable

\section{Funding}

The study did not receive any funding.

\section{Competing interests}

The authors declare that they have no competing interests.

\section{Authors' contributions}

JKT and EB developed the methodology of the study. CA, AM, and JBF developed the study concept, and conducted formal analysis. BOA extracted the data. BOA and AS supervised and conducted quality assessment of the study. CA, AM, EB, JBF, JKT, BOA and AS drafted the manuscript and revised the manuscript critically for important intellectual content. All authors have read and approved the final manuscript.

\section{Ethics approval and consent to participate}

The DHS survey protocols and procedures are scrutinised and approved by the ethics committee of ORC Macro and partner organisations of participating countries such as the Ministry of Health or the Ministry of Education in the selected countries. The survey was therefore conducted with adherence to the ethical guidelines by those institutions and for the conduct of studies among minors and majors.

\section{Consent for publication}

Not applicable.

\section{Availability of data and materials}

The datasets used and/or analyzed in the current study are available from the corresponding author on reasonable request. Besides this, since we used data from Demographic and Health Survey which is publicly available for research. 


\section{References}

1. Dagnew, G. W., Asresie, M. B., \& Fekadu, G. A. Factors associated with sexually transmitted infections among sexually active men in Ethiopia. Further analysis of 2016 Ethiopian demographic and health survey data. PloS one. 2020; 15(5), e0232793.

2. Arakkal, G. K., Damarla, S. V., Kasetty, H. K., \& Chintagunta, S. R. Changing trends in sexually transmitted infection (STI) clinic attendees-Current scenario. Int J Med Sci Public Health. 2014; 3(10), 1215-18.

3. Newman, L., Rowley, J., Vander Hoorn, S., Wijesooriya, N. S., Unemo, M., Low, N., ... \& Temmerman, M. Global estimates of the prevalence and incidence of four curable sexually transmitted infections in 2012 based on systematic review and global reporting. PloS one. 2015; 10(12), e0143304.

4. Gios, L., Mirandola, M., Toskin, I., Marcus, U., Dudareva-Vizule, S., Sherriff, N., ... \& Rafila, A. Biobehavioural HIV and STI surveillance among men who have sex with men in Europe: the Sialon II protocols. BMC Public Health. 2016;16(1), 1-10.

5. Unemo, M., Bradshaw, C. S., Hocking, J. S., de Vries, H. J., Francis, S. C., Mabey, D., ... \& Fairley, C. K. Sexually transmitted infections: challenges ahead. The Lancet infectious diseases. 2017; 17(8), e235-e279.

6. Chesson, H. W., Mayaud, P. \& Aral, S. O. Sexually transmitted infections: Impact and costeffectiveness of prevention. In Holmes, K. K., Bertozzi, S., Bloom, B. R., \& Jha, P. (Eds.). Disease Control Priorities. 2017,203-232. Washington, DC: World Bank Publications.

7. Vos, T., Barber, R. M., Bell, B., Bertozzi-Villa, A., Biryukov, S., Bolliger, I., ... \& Brugha, T. S. Global, regional, and national incidence, prevalence, and years lived with disability for 301 acute and chronic diseases and injuries in 188 countries, 1990-2013: a systematic analysis for the Global Burden of Disease Study 2013. The Lancet.2015; 386(9995), 743-800.

8. Ngo, A. D., Ratliff, E. A., McCurdy, S. A., Ross, M. W., Markham, C., \& Pham, H. T. B. Health-seeking behaviour for sexually transmitted infections and HIV testing among female sex workers in Vietnam. AIDS care. 2007; 19(7), 878-887. https://doi.org/10.1080/09540120601163078

9. Zhang, D., Pan, H., Cui, B., Law, F., Farrar, J., \& Ba-Thein, W. Sexual behaviors and awareness of sexually transmitted infections among Chinese university students. The Journal of Infection in Developing Countries. 2013; 7(12), 966-974. https://doi.org/10.3855/jidc.3872

10. World Health Organization. Report on global sexually transmitted infection surveillance. 2018.

11. Nasirian, M., Hooshyar, S. H., Haghdoost, A. A., \& Karamouzian, M. How and where do we ask sensitive questions: self-reporting of STI-associated symptoms among the Iranian general population. International journal of health policy and management. 2018;7(8), 738.

12. Aggarwal, P., Bhattar, S., Sahani, S. K., Bhalla, P., \& Garg, V. K. Sexually transmitted infections and HIV in self reporting men who have sex with men: A two-year study from India. Journal of infection and public health. 2016; 9(5), 564-570. https://doi.org/10.1016/j.jiph.2015.12.007 
13. Abdul, R., Gerritsen, A. A., Mwangome, M., \& Geubbels, E. Prevalence of self-reported symptoms of sexually transmitted infections, knowledge and sexual behaviour among youth in semi-rural Tanzania in the period of adolescent friendly health services strategy implementation. $B M C$ infectious diseases. 2018; 18(1), 1-10.

14. Najmabadi, K. M., \& Sharifi, F. Sexual education and women empowerment in health: a review of the literature. International Journal of Women's Health and Reproduction Sciences. 2019; 7(2), 150-155.

15. Ahinkorah, B. O., Hagan Jr, J. E., Seidu, A. A., Mintah, J. K., Sambah, F., Schack, T., \& Hormenu, T. Examining pregnancy related socio-cultural factors among adolescent girls in the Komenda-EdinaEguafo-Abrem municipality in the central region of Ghana: a case-control study. Frontiers in public health. 2019; 7, 93. https://doi.org/10.3389/fpubh.2019.00093

16. Wiyeh, A. B., Mome, R. K., Mahasha, P. W., Kongnyuy, E. J., \& Wiysonge, C. S. Effectiveness of the female condom in preventing HIV and sexually transmitted infections: a systematic review and metaanalysis. BMC public health. 2020; 20(1), 1-17.

17. Bain, L. E. Mandatory pre-abortion counseling is a barrier to accessing safe abortion services. The Pan African Medical Journal. 2020; 35.

18. Dodoo, N. D., Atiglo, D. Y., Biney, A. A., Alhassan, N., Peterson, M. B., \& Dodoo, F. N. A. Does financial autonomy imply reproductive and sexual autonomy? Evidence from urban poor women in Accra, Ghana. African Studies. 2019; 78(4), 477-495.

19. Prata, N., Fraser, A., Huchko, M. J., Gipson, J. D., Withers, M., Lewis, S., ... \& Upadhyay, U. D. Women's empowerment and family planning: A review of the literature. Journal of biosocial science. 2017; 49(6), 713-743. https://doi.org/10.1017/S0021932016000663

20. Ahinkorah, B. O., Dickson, K. S., \& Seidu, A. A. Women decision-making capacity and intimate partner violence among women in sub-Saharan Africa. Archives of Public Health. 2018; 76(1), 1-10.

21. Memiah, P., Opanga, Y., Bond, T., Cook, C., Mwangi, M., Fried, J., ... \& Machira, Y. W. Is sexual autonomy a protective factor for neonatal, child, and infant mortality? A multi-country analysis. Plos one. 2019; 14(2), e0212413.

22. Seidu, A. A., Ahinkorah, B. O., Dadzie, L. K., Tetteh, J. K., Agbaglo, E., Okyere, J., ... \& Schack, T. A multicountry cross-sectional study of self-reported sexually transmitted infections among sexually active men in sub-Saharan Africa. BMC Public Health. 2020; 20(1), 1-11. https://doi.org/10.1186/s12889020-09996-5

23. Wandera, S. O., Kwagala, B., \& Ntozi, J. Prevalence and risk factors for self-reported noncommunicable diseases among older Ugandans: a cross-sectional study. Global Health Action. 2015;8(1), 27923. https://doi.org/10.3402/gha.v8.27923

24. Wandera, S. O., Golaz, V., Kwagala, B., \& Ntozi, J. Factors associated with self-reported ill health among older Ugandans: a cross sectional study. Archives of gerontology and geriatrics. 2015;61(2), 231-239. https://doi.org/10.1016/j.archger.2015.05.006.

25. Corsi, D. J., Neuman, M., Finlay, J. E., \& Subramanian, S. Demographic and health surveys: A profile. International Journal of Epidemiology. 2012; 41(6), 1602-1613. 
26. Aliaga, A., \& Ruilin, R. Cluster optimal sample size for demographic and health surveys. Paper presented at the 7th International Conference on Teaching Statistics-ICOTS. 2006.

27. Von Elm, E., Altman, D. G., Egger, M., Pocock, S. J., Gøtzsche, P. C., Vandenbroucke, J. P., \& Initiative, S. The Strengthening the Reporting of Observational Studies in Epidemiology (STROBE) Statement: Guidelines for reporting observational studies. International Journal of Surgery. 2014; 12(12), 14951499.

28. Wandera, S. O., Ntozi, J. P., \& Kwagala, B. Spousal sexual violence, sexual behavior and sexually transmitted infections among ever-married women in Uganda. African Population Studies. 2010; 24(1-2).

29. Kishor, S., \& Johnson, K. Reproductive health and domestic violence: Are the poorest women uniquely disadvantaged? Demography. 2006; 43(2), 293-307.

30. Dude, A. M. Spousal intimate partner violence is associated with HIV and other STIs among married Rwandan women. AIDS and Behavior. 2011; 15(1), 142-152.

31. McClintock, H. F., \& Dulak, S. L. Intimate partner violence and sexually transmitted infections among women in Sub-Saharan Africa. Journal of immigrant and minority health. 2020; 1-8.

32. Ginindza, T. G., Stefan, C. D., Tsoka-Gwegweni, J. M., Dlamini, X., Jolly, P. E., Weiderpass, E., ... \& Sartorius, B. Prevalence and risk factors associated with sexually transmitted infections (STIs) among women of reproductive age in Swaziland. Infectious agents and cancer. 2017; 12(1), 1-12.

33. Nankinga, O., Misinde, C., \& Kwagala, B. Gender relations, sexual behaviour, and risk of contracting sexually transmitted infections among women in union in Uganda. BMC Public Health. 2016; 16(1), $1-11$.

34. World Health Organization. Global health sector strategy on sexually transmitted infections 20162021: toward ending STIS(No. WHO/RHR/16.09). World Health Organization. 2016.

35. World Health Organization. Global incidence and prevalence of selected curable sexually transmitted infections-2008. World Health Organization.2012.

36. DHS Program. Guide to DHS statistics. 2018. https://dhsprogram.com/pubs/pdf/DHSG1/Guide_to_DHS_Statistics_DHS-7.pdf. Accessed 15th March 2021

\section{Figures}




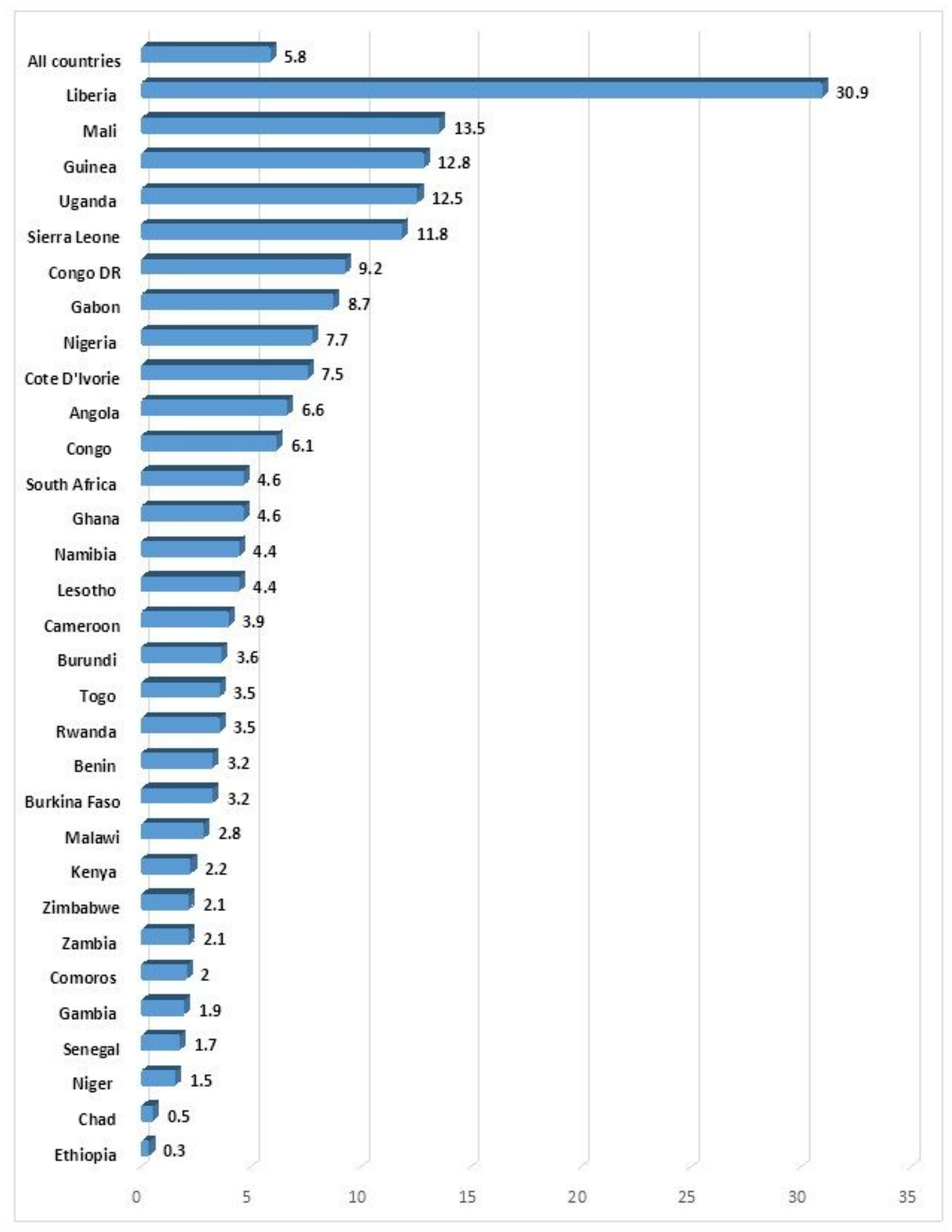

\section{Figure 1}

Prevalence of self-reported STI among women in sexual union in SSA 


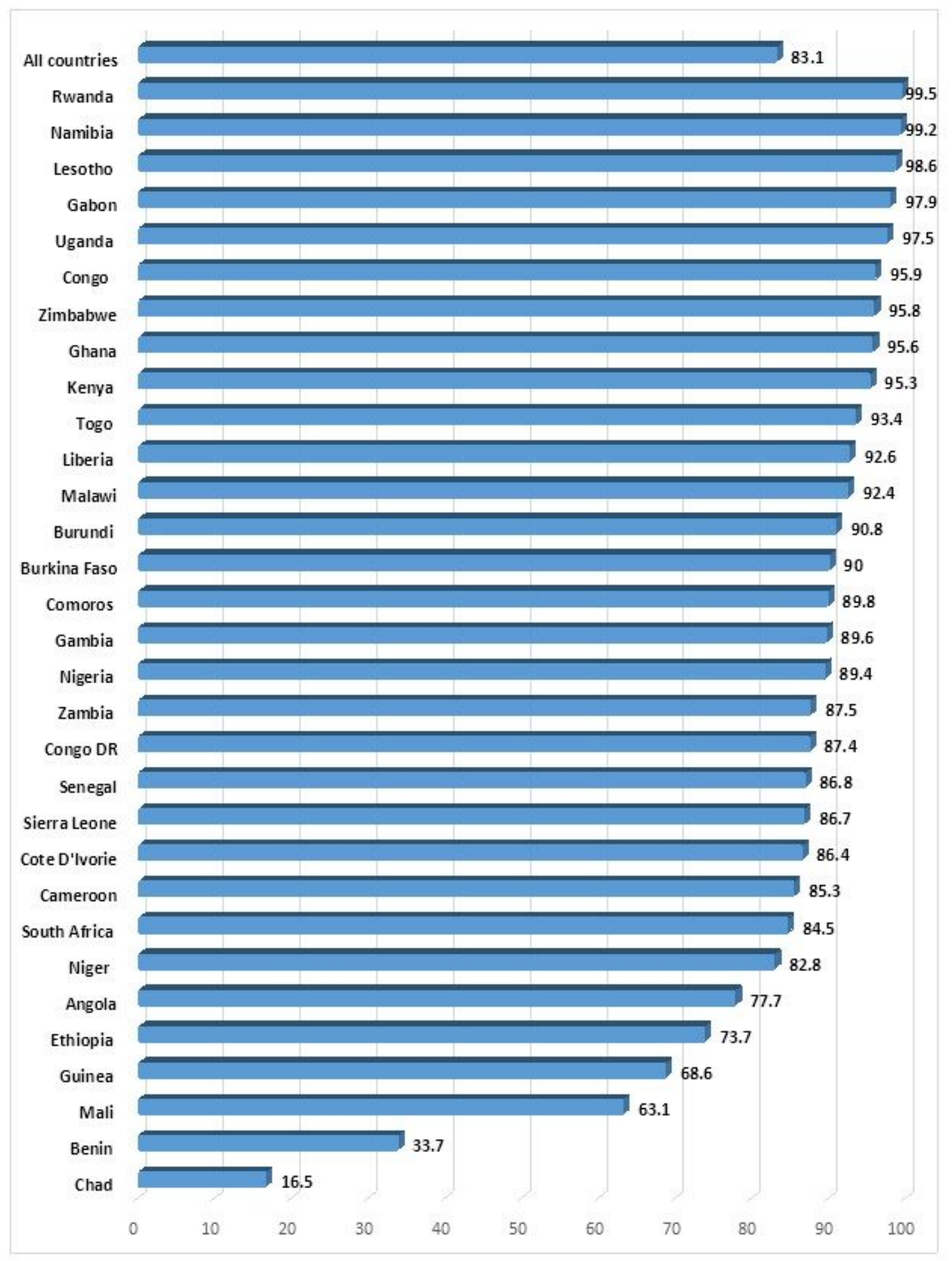

\section{Figure 2}

Prevalence of sexual autonomy among women in sexual union in SSA 